\title{
Temperando o conhecimento: narrativas míticas
}

Tereza Virgínia Ribeiro Barbosa* Universidade Federal de Minas Gerais

\section{Introdução ${ }^{1}$}

\section{Eurípides}

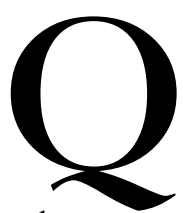

ualquer estudioso de cultura clássica vive acostumado e se satisfaz plenamente com fragmentos e ruínas. Não há lástima nisso, porque, nessa arqueologia, descobrem-se tesouros: palavras preciosas que reconstroem mundos e pensamentos. Para introduzir nosso tema - o mito, palavra absurdamente rica tanto no passado quanto no presente - vamos buscar uma outra preciosidade: o particípio verbal

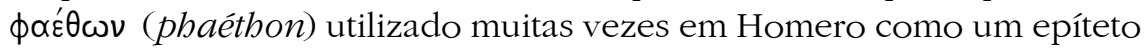
de Hélios. ${ }^{2} \mathrm{O}$ termo significa 'brilhante'.

Faetonte, hoje, para aqueles que desconhecem a língua grega, com ou sem brilho, é um grande tesouro perdido e encontrado em meio a vestígios verbais. É, também, o nome de uma tragédia perdida - para ser mais fascinante - de Eurípides, da qual restam somente fragmentos. Faetonte (frag. Nauck, 779), portanto, dará início ao nosso assunto. O trecho escolhido, dentre alguns outros vestígios escassos, é parte da descrição da

* Doutora em Lingüística, professora de Língua e Literatura Grega da Faculdade de Letras da Universidade Federal de Minas Gerais.

${ }^{1}$ Versão resumida desse artigo foi publicada nos anais do ENCONTRO REGIONAL DA ABRALIC de 2005.

2 Esse nome é, em outros contextos, aplicado a um cavalo de Eos, na Odisséia, 23, 246 e a uma das filhas de Hélios, фá́日ovơ (phaéthousa), Odisséia, 12, 132. Na literatura latina, Virgílio, na Eneida, 5, 105, denomina Faetonte ao próprio deus sol. 
queda de Faetonte, ou, em outros termos, da queda de 'Brilhante'. Um pedagogo/mestre ${ }^{3}$ dá instruções para que o jovem Faetonte, que na tragédia aparece como filho de Hélios, possa guiar apropriadamente o carro do sol:

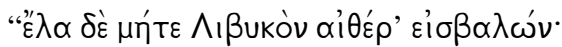

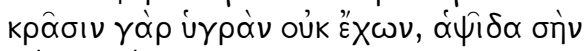

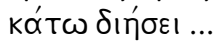

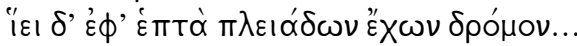

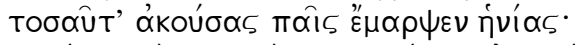

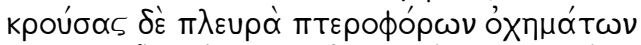

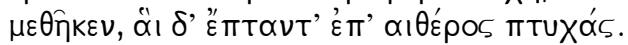
$\pi \alpha T \dot{\rho} \rho$ ' őmı

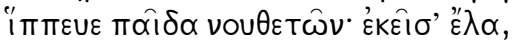

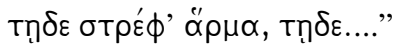

"Avança, mas não joga para o éter líbio, por que ele não tem clima úmido e tua roda, para baixo, vai derrapar ${ }^{4} \ldots$

Vai fazendo corrida acima das sete Plêiades ..."

Ouvindo tais o menino agarrou as rédeas

Açoitando o flanco das aladas condutoras,

Deixou [as] ir; elas, então, voam pelos recôncavos do éter.

O pai, atrás, montado no dorso de Sírio

Cavalgava advertindo o menino: por aqui, vai

Aqui, vira o carro, aqui." (EURÍPIDES, séc. V a. C, fragmento)

Vimos, portanto, que, nesse fragmento, o instrutor de Faetonte orienta seu discípulo já muito impaciente ${ }^{5}$ para empreender a jornada que lhe possibilitaria fabricar um dia de sol. Duas coisas serão necessárias para o aprendiz: não adentrar um ar sem mistura e seguir as instruções que lhe foram dadas. Infelizmente, nosso inexperiente amigo não obedece e, audacioso, conduz o carro para as bandas da Líbia, onde o ar é seco e puro. Dessa forma, despenca do alto e mergulha em águas pouco favoráveis.

3 Adotamos, de Lesky, a identificação de 'pedagogo' para a personagem que fala no trecho. Apud. DIGGLE (ed.), 1970, p. 41.

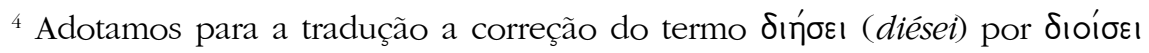
(dioísei). DIGGLE (ed.), 1970, p.136.

5 A impaciência de Faetonte é dada pela forma aoristo do verbo $\mu \alpha \dot{\rho} \rho \pi \tau \omega$ (márpto). Cf. DIGGLE (ed.), 1970, p. 137. 
Esse pequeno trecho fornece para nós um dado interessante; dele, destacaremos a palavra kpôøı ( krasin), ${ }^{6}$ que significa estritamente 'mistura de elementos' - frio com quente, úmido com seco. O ar líbio da região à volta do Egito seria, portanto, um ar seco (xerós), sem mistura. Conclusão temporária: Para o carro de Faetonte, a mistura no ar tem vantagens. Enquadra-se, dentro dessa direção de pensamento, também o estudo da narrativa mítica já que ela se conforma na situação de mistura quando se utiliza tanto da sensação e da experiência de coisas tangíveis (aîsthesis kai práxis) quanto do raciocínio (nóesis) que vai para além dos dados fisicamente percebidos. Por isso ela é capaz de lidar tanto com coisas práticas quanto com as coisas abstratas, menos tangíveis pelos sentidos e, desse modo, pode alcançar o brilho de conhecimento sincrético.

\section{Luciano}

Ainda com Faetonte em mente, mas passando para um outro contexto, vamos ter oportunidade de entender um pouco mais acerca do mito, bem como identificar a partir de que procedimentos as narrativas míticas são construídas. Tomamos um prolaliā de Luciano de Samósata (séc. II), intitulado Acerca do âmbar ou Os cisnes no qual Luciano conta que teria aprendido serem os álamos, às margens do rio Erídano, irmãs de Faetonte, as quais derramam lágrimas pelo irmão querido que havia perecido naquele rio ao cair do carro do sol. ${ }^{8} \mathrm{~A}$ história completa-se com uma narrativa sobre

${ }^{6}$ Que aqui traduzimos por clima.

7 Prolaliá é nome dado a um pequeno exercício de retórica.

${ }^{8}$ A tradição de árvores que choram continua até hoje. Não são histórias tão disparatadas, caso contrário, teriam caído no esquecimento. Há rastros dos álamos do rio Erídano. Passando pelas árvores que choram sangue e palavras em Virgílio (VIRGILIO, Eneida, III, 20-102) e Dante (DANTE, Divina Comédia, canto XIII, vv. 28-45), podemos chegar até a Amazônia onde as árvores choram borracha. Entre nós, o nome dado para essas árvores é seringueira ou árvore da borracha. Das 'lágrimas' dessas árvores muitos enriqueceram. Os nativos de Quito chamavam-na Cau-chu ('pau que dá leite'). Seu nome científico é Hevea brasiliensis, planta nativa na Região Amazônica que cresce, principalmente, às margens de rios. Costuma ser encontrada também em lugares inundáveis da mata de terra firme. 
a origem do âmbar ${ }^{9}$ que seria nada mais, nada menos, que lágrimas solidificadas das Helíades que choram ainda pelo seu irmão. Acreditando poder recolher todo o âmbar que coubesse em sua túnica, Luciano confessa que visitou o rio Erídano e, que às suas margens, pôs-se a inquirir os nativos sobre tal história. Estes argumentaram com o desiludido narrador e por fim apelaram para uma prova irrefutável: a razoabilidade. Seria inconcebível que eles, constrangidos, pela necessidade de sobrevivência, vivessem a remar e arrastar barcos contra a corrente, fazendo inúmeras viagens com curiosos e oportunistas, ao preço de dois míseros óbolos em lugar de, numa região onde álamos chorassem âmbar, simplesmente colher a riqueza 'chorada' das árvores? Assim, para a frustração daquele que sonhava com um enriquecimento rápido, o testemunho dos nativos - de que não havia, naquele local, nem álamos nem âmbar - é a destruição de um futuro promissor. Entretanto, Luciano, num último esforço, pergunta aos nativos da região acerca dos cisnes e de seu canto. ${ }^{10}$ Os nativos, obviamente, zombam de mais essa ingenuidade de nosso narrador, afinal cisnes não cantam: grasnam.

Ao fim de seu exercício retórico, destruídas as ilusões míticas, Luciano - indigente de imagens fabulosas, brilhantes e excitantes ouvidas desde pequeno, constrói - para explicar seu raciocínio renovado - esta teoria: mitos são histórias carregadas de exagero que descrevem um tema de forma a obter o mesmo efeito amplificado, tal como o que ocorre pela submersão de objetos na água. Bela imagem. Para explicar sua teoria vamos misturar dois meios de entendimento, a saber, a física e o estudo do pensamento.

\footnotetext{
9 O âmbar é um 'mineralóide' transparente e cristalino de grande valor comercial, O termo grego para denominar o âmbar é electron.

${ }^{10}$ Os cisnes têm fama de entoar uma belíssima melodia quando vão morrer. Essa fama se comprova em muitos fragmentos de poesia e, sobretudo, em uma fábula de Esopo que narra que um homem teria criado juntos um cisne e um ganso. O cisne foi criado para que seu dono ouvisse dele sua última melodia, o ganso para ser comido. Certa vez, estando já escuro, o homem resolveu preparar sua refeição e foi buscar o ganso. Como estivesse difícil distinguir as aves uma da outra, o dono das aves pegou, por engano, o cisne que se pôs logo a cantar. Diante disso, ele compreendeu imediatamente seu engano, deixou o animal viver e pegou o ganso para sua refeição.
} 
Vamos tratá-los como um símile. ${ }^{11}$ Tal como a refração na água, o mito é a refração no entendimento. Assim, acontece que um raio de luz, quando passa do ar para a água, muda de sentido. O seu deslocamento provoca a ampliação dos objetos que estiverem submergidos na água e aquele que observa através da água ou do vidro vê esses objetos ampliados e fora da posição em que realmente estão. Da mesma forma, um raio de sabedoria, um insight, quando passa do meio abstrato para o meio das experiências e sensações, muda o sentido da compreensão.

Retornemos Luciano. A sua decepção leva-o a rejeitar a narrativa mítica e a apresentar o discurso simples e sem qualquer mitologia (haploikòn kai ámython) como um discurso ideal. Em seu texto, Luciano propõe uma ação depurativa: defender o uso de um estilo narrativo direto e elegante e evitar as narrativas construídas por imagens compósitas, misturadas, fantasiosas e ampliadas. Admitamos que o mito seja uma interpretação desviante e perigosa, afinal, Platão, já no séc. IV a. C. advertiu-nos sobre esse perigo (República 381 e).

Que devemos fazer no processo educativo, proibir os mitos?

11 Segundo Kirk, apud ROCHA PEREIRA, 1998, p. 73, "Os símiles servem para cristalizar, numa esfera mais próxima do entendimento do ouvinte, um espetáculo, som ou estado de espírito; e para aliviar a dureza e monotonia potencial da guerra, apresentando bruscamente uma cena diferente, pacífica e doméstica mesmo.”. Fränkel, apud ROCHA PEREIRA, idem, ibidem afirma que: "A epopéia antiga só conhece a exposição linear; e o símile coloca uma nova linha paralela junto da narrativa. (...) Os símiles alargam o horizonte, parando momentaneamente a acção em curso, para intercalar uma imagem de conjunto da situação.” Rocha Pereira, ela própria, define o símile como uma comparação estendida a qual compara uma ação compósita com outra ação compósita e que vem introduzida por expressões do tipo 'tal como', 'assim como'. Para Lausberg (LAUSBERG, 1993, 238-9), o símile é uma figura que elabora a afinidade de conceitos por acumulação. Símile = semelhante. Pela intensidade semântica do conteúdo da palavra e valendo do estranhamento condensam-se duas imagens diferentes. Na formulação mais ou menos longa a comparação é tornada compreensível por meio da pormenorização intensificante. Os símiles são empregados para processos humanos finitos e perceptíveis pelos sentidos, para processos da vida da natureza e para processos humanos e supraterrenos não perceptíveis. 


\section{Plutarco}

Plutarco de Queronea (séc. I) no tratado intitulado Sobre a educação dos Filhos ou De Liberis, ao tratar do cuidado com o estilo, demonstra que um bom educador deve preocupar-se em desenvolver na criança, simultaneamente, o gosto e a prática pela filosofia e pelas artes. O autor justifica-se afirmando que as artes são fontes de prazer e que a filosofia é remédio para os sofrimentos e para as debilidades da alma. Mas, nesse ponto, parece-nos que há uma incoerência na metodologia plutarquiana. ${ }^{12} \mathrm{Como}$ sabemos, a filosofia privilegia a verdade enquanto as artes buscam a mimesis. Nesses termos, a prática e o gosto pelas artes não desenvolvem o zelo pela verdade (desde a famosa comparação de Aristóteles na Poética ${ }^{13}$ ). De fato, essas questões fazem-nos recordar as advertências de Luciano. Felizmente, tal incoerência metodológica será resolvida num outro tratado do mesmo autor, De audientis poetis ou Como o jovem deve escutar a Poesia, destinado a mestres de poesia. De audientis poetis intenta explicar textos poéticos acusados de ter um caráter condenável, apelativo, espetacular, exagerado e mentiroso. Na análise dos referidos textos, Plutarco repara que os jovens se comprazem na variedade e na fantasia, julgam a monotonia cansativa e árdua ${ }^{14}$ e só se entusiasmam quando lêem doutrinas filosóficas misturadas à mitologia. Depois da apresentação de trechos de obras de vários poetas, o educador conclui, tal como o pedagogo de Faetonte, que, no processo educativo, deve-se observar a mistura como um bom exercício para o discernimento. Para ele cabe ao mestre dar uma direção de leitura voltada para a verdade e para isso o meio misturado é muito apropriado para a

\footnotetext{
${ }^{12}$ Plutarco, em De audientis poetis $17 \mathrm{~d}$, afirma que não é fácil compreender a verdade e que a arte poética - em absoluto - não se preocupa com ela, mas com a mimesis. Para ele, captar a verdade na realidade ordinária é uma ciência difícil, mesmo para os filósofos (17 D). O prazer do reconhecimento, no mito que narra um fato com imagens diferentes do real, existe independentemente de sua retratação perfeita do real. $c f$. Aristóteles, Poética, 1448 b.

13 Poética, 1451 b.

${ }_{14}$ De Liberis, 7c. Com a mesma intenção, em De audientis poetis, 15c-f, Plutarco cita Homero - Odisséia IV, 230 - que afirma que as drogas misturadas podem ser ao mesmo tempo veneno ou remédio.
} 
aprendizagem do distinguir o bem e o mal. Por esse raciocínio, a narrativa fantasiosa inserida na poesia é acolhida e a mitologia passa a ser chamada de 'merenda escolar' por oposição à refeição completa, a saber, a filosofia; a mitologia é também chamada de ametista enquanto a filosofia é pedra preciosa de valor eterno (De audientis poetis, 14e). Plutarco afirma que a mitologia é como a cabeça de um polvo, que é saborosa, mas causa pesadelos. Nelas há algo bom e algo mau. Em outro passo, no mesmo sentido, ele garante que a mescla de vinho com água suprime o mau sem destruir o útil (De audientis poetis, 15e). A mitologia, embora perturbadora e vacilante, é agradável, útil e alimenta a alma. Portanto, o que se espera no processo educativo é o ensino das regras do jogo. O jovem deve ser capaz de discernir entre o que fosse inventado para veicular uma verdade difícil de exprimir e o que fosse inventado para o assombro dos homens ( $D e$ audientis poetis, 20f). Para o educador, nem o metro, nem a figura retórica, nem a majestade do estilo, nem o emprego de metáforas, nem a harmonia e, finalmente, nem a composição possuem tanto atrativo e graça quanto uma narrativa mítica bem construída (De audientis poetis, 16b).

\section{Apuleio}

Comentaremos a partir de agora o processo de inserção de uma narrativa mítica famosa, a história de Psique, no romance helenístico intitulado O asno de Apuleio. A história de Psique é parte de uma trama bem ajustada para compor uma narrativa variada, agradável e fantasiosa. Afinal, já no início, o narrador afirma:

Muitas fábulas quero apresentar-te, em variada seqüência, nesta conversa de estilo milesiano, e agradar teus benévolos ouvintes com um álacre sussurro, no caso em que não desdenhes ler o papiro egípcio, coberto de letras gravadas pelo fino estilete de um caniço do Nilo. Verás, encantado, seres humanos, despojados de sua imagem e condição, tomarem outra forma; depois, ao contrário, e por uma ordem inversa, serem convertidos em si mesmos. (APULEIO, O asno de ouro, séc. I d. C, livro $1, \$ 1)^{15}$

Todo o romance é uma longa história de metamorfoses. Lúcio, depois de muitas peripécias, transformado em asno, cai nas mãos de bandidos e

\footnotetext{
${ }^{15}$ As citações do romance são feitas a partir da tradução de Ruth Guimarães.
} 
segue com eles para um esconderijo. Abrigados das autoridades locais, os salteadores, em meio a muitos acidentes, raptam uma jovem prestes a casarse e levam-na para seu covil. A moça, com a cabeça entre os joelhos, amedrontada e inconformada, põe-se a chorar desesperadamente. Compadecendo-se de seus sofrimentos, a velha empregada ${ }^{16}$ dos assaltantes apazigua a dor da jovem contando-lhe a história de Eros e Psique, ou, mais especificamente, a história de como Psique se tornou a esposa imortal de Eros e a mãe de Volúpia.

Resumimos a história narrada. A terrível Afrodite encarregará seu filho, Eros, de vingá-la, pois a fama da belíssima Psique (Sopro de vida) propagou-se pela terra e estava prestes a superar a da própria deusa. Eros, no entanto, apaixona-se por Psique e une-se a ela sob a condição de nunca poder ser visto. Assim, o Amor, sempre invisível e ardente para Psique, é, na fala das irmãs da jovem, 'uma horrível serpente, um réptil de tortuosos anéis, com o pescoço estufado de baba sanguinolenta, de um veneno temível, [com] a goela hiante e profunda (...)', uma 'besta nupcial', ${ }^{17}$ 'que haverá te devorar'. ${ }^{18}$ Curioso, Eros na história que vai dar origem ao conto de Fadas $A$ bela e a fera, é um monstro assustador e acabará percorrendo narrativas inúmeras para ser chamado simplesmente de 'bête'. Todavia, não estamos interessados na história de Eros e Psique, interessa-nos tão somente que conhecimento auferimos desse mito e qual a função dessa história mirabolante. Sobre esse assunto, o próprio Lúcio, protagonista do romance, na pele de asno, para nós, aponta uma direção:

"A velha, que misturava seus suspiros às queixas da moça replicou então: 'Mocinha, ânimo, e não te deixes apavorar pelos vãos fingimentos de um sonho. As imagens que o sono nos traz, quando o dia chega passam por mentirosas, e até acontece que as visões da noite tenham efeito contrário do que nos apresentam. Assim, chorar, ser espancado, ou então ser degolado, pressagia lucros e bons proveitos. Ao passo que rir, encher a pança de quitutes e de doces, ou saborear o prazer do amor,

${ }^{16}$ Platão faz referência a este costume de velhas senhoras de contar

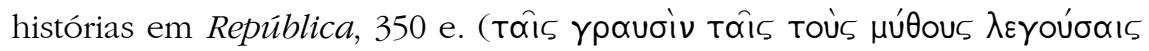
- taîs grausin taîs tus mythous legúsai- as velhas contadoras de mitos).

${ }^{17}$ Asinus Aureus, livro V, $\mathbb{} 17$ - serpentem, veneno noxio colla sanguinantem biantemque ingluvie profunda.

${ }^{18}$ Idem, V, $₫ 18$. 
significa que a tristeza, a doença, e mil outras desgraças estão para vir. Demais, eu poderei te distrair com lindas histórias e contos de gente velha.' E começou." (APULEIO, O asno de ouro, séc. I d. C, livro 4, \$28)

Aí está uma das funções das narrativas míticas: é o entretenimento que visa a um apaziguamento da dor pela compreensão emocional, física e intelectual. Em outro passo do romance, Lúcio, ao consolar um amigo, diz para o leitor: "Procurei um leito para reparar-lhe as forças, fi-lo comer à farta e beber quanto quisesse, e acalmei-o contando-lhe histórias." ${ }^{19}$

Apontada a função dada ao mito pela narrativa de Apuleio, podemos nos perguntar se essa narrativa nos auxilia no entendimento acerca do amor. Acreditamos que sim, desse mito compreendemos a natureza de Eros: a mais feroz de todas as feras selvagens, o dulcíssimo, o adorável monstro. ${ }^{20}$

Parece-nos, portanto, que o melhor caminho a tomar seja tratar os mitos como narrativas aplicadas que carregam uma função específica dentro de seu contexto cultural. Dessa forma, apesar de serem narrativas absurdas, carregadas de falácias, são também narrativas cheias de seriedade e dignidade que procedem de sua aplicação: concatenar experiências de diferentes campos (abstrato e sensitivo) e ensinar a apaziguar a dor. Talvez seja por isso que, embora sendo, em sua essência, ilógico, inverossímil ou impossível, às vezes imoral e quase sempre falso, o mito é compulsivo, fascinante, profundo e digno.

Portanto, desde Faetonte até Plutarco, parece-nos claro que o mito não é uma narrativa pura em razão de ele ter por alvo a realidade e de a realidade não nos ser dada categorizada nem pasteurizada.

Por outro lado, acusar o mito de ser uma narrativa construída a partir de imagens grotescas (entendemos por grotesco a prática da transferência de tudo o que é elevado, espiritual, ideal e abstrato para o plano material) tal como o fez Luciano, já não nos parece correto. O grotesco mítico, se lido à luz das ponderações de Bakhtin (BAKHTIN, 1999, p.17) pode ser assimilado como uma degradação positiva e regeneradora de um abstrato distante. Bakhtin afirma que a vida dupla, intensa e contraditória do grotesco constitui uma força. Talvez devêssemos entendê-lo como propõe Viegas (VIEGAS, 1994, p. 97): o mito é pensamento por imagens. E, numa leitura

\footnotetext{
19 Idem, I, $\int 7$.

${ }^{20}$ Asinus Aureus, livro V, $\mathbb{\complement} 22$. [Psique] videt omnium ferarum mitissimam dulcissimamque bestiam.
} 
mais radical talvez possamos afirmar que o mito é narrar através de imagens grotescas que, pela mistura, forjam aquilo que nunca vimos nem veremos, nem entenderemos, mas que já experimentamos e compreendemos.

\section{Temperando a narrativa}

Voltemos à teoria de Luciano da refração e dos objetos submersos na água. Busquemos o encantamento, o brilho de um entendimento que associa aisthesis e nóesis. Somente a quebra de um raio de luz que incide sobre a água pode nos revelar que ele é composto por vários outros raios de luz de cores diferentes. Somente através do deslocamento da luz podemos enxergar essa mesma luz em espectro. Guardemos a visão mítica e luminosa de um arco-íris formado pelo raio de luz que incide na água e se faz espectro. Deixemos a poesia conduzir o entendimento. Assim, a utilização dos mitos na educação cria condição tanto para a reflexão filosófica quanto para a reflexão poética, pois transita - em vai e vem - do concreto para o abstrato, do literal para o metafórico. É um processo de narrativa que se fundamenta em deslocamentos, misturas e trocas de meios; em variedade e com o intuito de captar o fluxo inexorável das coisas.

\section{Bibliografia}

ALIGHIERI, D. A Divina Comédia - Inferno. Trad. Italo Eugênio Mauro. São Paulo: Editora 34, 1998.

APUlEIO. O asno de ouro. Trad. R. Guimarães. São Paulo: Editora Cultrix, 1963.

ARISTÓTELES. Poética. Trad. e comm. E. de Sousa. Lisboa: Casa da moeda, s/d.

BAKHTIN, M. A cultura popular na Idade Média e no Renascimento: o contexto de François Rabelais. São Paulo-Brasília: HUCITEC-Edunb, 1999.

BRANDÃO, J. L. A poética do Hipocentauro. Belo Horizonte: Editora UFMG, 2001.

BURKERT, W. Mito e mitologia. Lisboa: Edições 70, 1991.

CALLOIS, R. O mito e o homem. Trad. J. C. dos Santos. Lisboa: Edições 70, s/d. EURIPIDES. Phathon. DIGGLE, J. (Ed.) Cambridge: Cambridge University Press, 1970. 
GOMBRICH, E. H. Meditações sobre um cavalinho de pau. São Paulo: Ed. Univ. de São Paulo, 1999.

HOMERO. The Odissey of Homer. W. B. Stanford (ed.) London: Macmillan Education LTD., 1988.

JOLLES, A. Formas simples. Trad. A. Cabral. São Paulo: Editora Cultrix, 1976.

KORUS, K. The theory of humour in Lucian of Samosata. Eos. Commentarii Societatis Philologae Polonorum. Kraków. Vol. LXXII, p. 295-313, 1984.

LUCIANO. Oeuvres. Tomo I. A propos de l'ambre ou des cygnes. Paris: Les Belles Lettres, 1993.

NAUCK, A. Tragicorum Graecorum Fragmenta. Supplementum adjecit Bruno Snell. Belim: Georg Olms Hisdesheim, 1964.

PLATÃO, Repubblica. Milão: Grandi Tascalili Economici, 1997.

PLUTARCO. Sobre la educación de los hijos. Moralia. v. I. Trad. introd e notas de C. Morales e J. Gracía lópez. Madrid: Editorial Gredos, 1992.

. Como debe el joven escuchar la poesia. Moralia. v. I. Trad. introd e notas de C. Morales e J. García López. Madrid: Editorial Gredos, 1992.

L'education des enfants. Oeuvres morales. Tome I Paris: Les Belles Lettres, 1987.

Comment lire les poètes. Oeuvres morales. Tome I Paris: Les Belles Lettres, 1987.

ROCHA PEREIRA, M. H. Estudos de História da Cultura Clássica. v. I. Lisboa: Fundação Calouste Gulbenkian, 1998.

VEYNE, P. Acreditavam os gregos em seus mitos? Trad. H. Gonzáles \& M. M. Nascimento. São Paulo: Editora Brasiliense, 1984.

VIEGAS, S. Mito: pensar por imagens. In: Cadernos de Textos no2 - Mito. Belo Horizonte: Núcleo de Filosofia Sônia Viegas, 1994, pp. 93-111.

O tempo na filosofia. In: Cadernos de Textos no2 - Mito. Belo Horizonte: Núcleo de Filosofia Sônia Viegas, 1994, pp. 69-82.

VIRGILIO. Eneida. Trad. Leopoldo Pereira. São Paulo: Edições Melhoramentos, s/d. 


\section{INTERNET}

http://www.gutenberg.net/etext/997 Costa, Reginaldo Brito da, Gonçalves, Paulo de Souza, Odalia-Rímoli, Adriana e Arruda, Eduardo José de. Melhoramento e conservação genética aplicados ao Desenvolvimento Local - o caso da seringueira (Hevea sp) In: Interações - Revista Internacional de Desenvolvimento Local. V. 1, N. 2, p. 51-58, Mar. 2001.

http://www.intratext.com/IXT/LAT0533/_P94.HTM Methamorphoses ou Assinus Aureus. Acesso 01/05/06.

\section{Resumo}

Retomamos o entendimento de mito desenvolvido por Luciano de Samósata, séc. II d. C., no prolaliá Acerca do âmbar ou Os cisnes. Nesse pequeno exercício retórico, o autor ataca o uso da narrativa mítica no processo educativo, qualificando-a de equivocada e comparando-a com as distorções visuais que um corpo submerso na água aparenta sofrer (refração). Em seguida, conjugamos o texto referido a dois tratados de Plutarco de Queronea, séc. I d. C. (De Liberis e De audientis poetis). Voltamos ao gênero ficcional, na intenção de definir o mito e utilizamos as sugestões de Apuleio, séc. II d. C., em seu romance O asno, acerca da função da narrativa mítica. Concluímos ampliando a aplicação da metáfora estabelecida por Luciano.

\section{Abstract}

We retake the myth agreement developed for Lucian (II d. C), in the prolalia Concerning the amber or The swans. In this small rhetorical exercise, the author attacks the use of mythical narrative in the educative process, by characterizing it as a kind of a mistake and comparing it with the visual distortions that a submerged body seems to suffer (refraction). After that, we conjugate the cited text and two Treatises of Plutarch of Queronea, (I d. C.), De Liberis and De poetis audientis. We come back to the ficcional genre, aiming at define the myth. Therefore, we use the suggestions of Apuleius (II d. C.) in his romance The golden ass, concerning the function of the mythical narrative. We conclude extending the application of the metaphor established by Lucian. 